\title{
Public opinion of the host country on migrants and their problems
}

\author{
Khusnutdinova Lyailya*, and Nazarova Zagida \\ Ufa State Petroleum Technological University (USPTU), st. Kosmonavtov 1, 450064 Ufa, Russian \\ Federation
}

\begin{abstract}
The article presents the results of a sociological survey on migration problems in the Republic of Bashkortostan. The survey was conducted in several stages, where different age groups were interviewed, including schoolchildren and students. In addition to the above, the study involved managers, heads of national public organizations, research supervisors and teachers who, by their role, came into contact or worked directly with migrants and were included in the survey as experts. The study showed that the topic of migration is relevant and important for the residents of the Republic. Bashkortostan and its capital Ufa have significant integration potential, where the majority of citizens are positive about labor migrants and the weakness of migrant-phobic attitudes.
\end{abstract}

\section{Introduction}

Currently, one of the most pressing problems of Russian society is the participation of young people in political life. This is connected with the conditions of de-ideologization, the state's withdrawal from paternalistic aspirations, and the growth of anarchic, rebellious, and religious and nationalist sentiments. The increasing politicization of ethnicity is accompanied by new trends and manifestations in ethno-political, ethno-social, ethnocultural and other processes, forcing the search for new theoretical and methodological means of its research. External migration also leaves a global footprint in the ethno-political space of the host country, creating a need to study the practices of socialization, integration and acculturation of non-ethnic groups, as well as forms of their identification activity in the ethno-political and ethno-social space, including at the regional level. The structural changes that have taken place in the ethno-political space of the Russian region in recent decades make it possible to distinguish the ethnic identity of the Diaspora as a special phenomenon that contains not only the resources of the integration model of interaction, but also the potential for conflict. For modern Russia, an important element of "soft security" is inter-ethnic and inter-regional relations on the ground and, above all, the problems of relations between migrants and the local population.

The process of adaptation and integration of migrants into the local multi-ethnic community is often difficult due to the existing migrant phobia in society [1]. Sometimes public opinion is infected with "everyday xenophobia" [2], which manifests itself in

\footnotetext{
* Corresponding author: lavanda-55@mail.ru
} 
everyday life situations, but can seriously harm the rapprochement of migrants with the local population. Some politicians and government representatives often use such public opinion to justify certain managerial actions [3]. The conservative position on migration is particularly evident during the election period, using the anti-migrant mood of the population. The negative attitude towards migrants also contributes to the development of corruption among representatives of various organizations that allow themselves illegal actions [4].

According to the 2002 and 2010 population censuses, the total number of Tajiks, Uzbeks, and Kyrgyz permanently residing in the Russian Federation has almost doubled [5]. The remaining non-ethnic groups eventually form ethno-cultural organizations and public organizations (associations) with a fixed political and legal status of national-cultural autonomies (NCAS), as evidenced by their identification activity at all levels of the ethnopolitical space [6].

The purpose of our research is to study the public opinion of the local population and experts on migration issues; to identify how different segments of the population perceive migrants; to assess the degree of tolerance to migrants.

To achieve this goal, a sociological survey of the local population, experts, schoolchildren and students was conducted in the Republic of Bashkortostan in the spring and autumn of 2018 using a standardized questionnaire.

The study of public opinion on migration issues allowed us to significantly supplement and expand the understanding in modern science of the latest trends in the migration movement of the population, the role and influence of public and national-cultural organizations on the adaptation and integration of migrants into a new multi-ethnic community. The results obtained in our study can also be used as a theoretical and practical basis for new research on migration processes in Russia and for optimizing the sociocultural adaptation and integration of migrants into the local community through the development of special state programs, concepts, and recommendations.

\section{Data and methods}

The methodological basis of the research is the fundamental works of Russian scientists - L. Rybakovsky, Zh. Zayonchkovskaya, V. Mukomel, N. Lebedeva, V. Tishkov, T. Yudina, I. Badyshtova, R. Galina, I. Gabdrafikov and others, who study trends, types and forms of migration, including the processes of adaptation and integration of migrants into the local multi-ethnic community. The empirical basis of the study is the results of a sociological study of the local population, experts, schoolchildren and students of the Republic of Bashkortostan on the study of public opinion on migration issues, conducted by the authors in the spring-autumn of 2018 in this region. The tools are based on a standardized mass survey questionnaire. In this study, a territorial sample was used. The results obtained were subjected to analytical description, correlation analysis, along with methods of descriptive statistics, etc.

\section{Results}

The study involved 530 people. During the first stage of the study, conducted from April to May 2018, 300 young respondents were interviewed: 150 students of secondary educational institutions (20 of them are pupils of school No. $85 \mathrm{Ufa}, 30$ pupils of mathematical gymnasium No. 93 Ufa, 30 pupils of the Chekmagush village gymnasium, 49 students of the Bashkir architectural and construction college, 18 students of the Ufa mechanical and technological college), as well as 150 students of higher educational institutions (including 
39 students of the Bashkir state agrarian university, 30 students of the Ufa state petroleum technological university, 34 students of the Ufa state petroleum technological university institute of economics and service, 25 students of the Bashkir cooperative institute, 20 students of the Ufa state aviation technical university, 1 student of the Bashkir state university and 1 student of the Bashkir academy of public service and management).

During the second stage of the study, which was conducted in the period from October to November 2018, 300 more people were interviewed, including 260 residents of the city of Ufa, 40 residents of the village of Chekmagush.

Socio-demographic composition of the respondents: men $-40 \%$, women $-60 \%$.

By age, the respondents were divided into the following groups: $18-29$ years $-45 \%$, $30-59$ years $-44 \%, 60$ and older $-11 \%$. By the time of the survey, $53 \%$ of respondents were working, $20 \%$ were studying, $8 \%$ were retired, $2.9 \%$ were unemployed, $3 \%$ were engaged in household work, and $13 \%$ indicated otherwise.

$97 \%$ of respondents have been living in Bashkiria for more than 10 years, 84\% since birth, 9\% came from another region of Russia, 6\% from another state, including the republics of the former USSR.

The survey data showed that the responses of respondents of all categories of citizens (both the population and students) to almost all questions are similar, there is no noticeable difference in their attitude to certain aspects related to the topic of migration and migration policy.

There are no fundamental differences in the distribution of the population's responses to the question of which professions should employ foreign migrants in the region. The basic answers of respondents were distributed in those areas that require hard physical are less prestigious for the local population, which so occupied the main part of labor migrants: cleaning and other housing services $16 \%$, building and road works $-16 \%$, agriculture $13 \%$, factories $-9 \%$, employment from citizens (smallholdings, nannies in families, etc.) $7 \%$, and trade - 8\% (in this case, respondents most likely meant market trade, where representatives of the countries of Central Asia and Transcaucasia are traditionally engaged). At the same time, the share of those who answered the question that migrants are not needed in any professions is $4 \%, 3 \%$ of respondents found it difficult to answer, and $4 \%$ offered their own answer.

When asked whether visitors from other countries take jobs away from local residents, the respondents ' responses differed. About half of the respondents from the general population said that local residents themselves do not want to take some jobs. According to $11 \%$ of the population, newcomers still take jobs from local residents, and about $1 / 3$ of respondents from the total population answered "both", i.e. newcomers take jobs from local residents, but local residents themselves do not want to take some jobs. A small percentage of respondents gave a different answer $3 \%, 5 \%$ of the population found it difficult to answer.

The survey confirmed the data of our previous surveys about the tolerant attitude of the population towards migrants and the weakness of migrant-phobic attitudes among them. Thus, $70 \%$, i.e. more than $2 / 3$ of the respondents are determined not to support pickets or other actions against foreign labor migrants if they occur. At the same time, about $8 \%$ would support such an action, while $6 \%$ gave a different answer, and $16 \%$ found it difficult to answer. It should be noted that the distribution of answers to this and previous questions is quite comparable with the data of surveys conducted by us on the topic of integration of migrants in previous years as part of the RSC research project.

Absolute majority (more than $90 \%$ ) of respondents said that it is necessary to teach migrants the Russian language, $47 \%$ support the idea of teaching migrants the Russian language. $1 / 5$ of the respondents answered Yes, but on the condition "only teach those who want to stay in Russia", and more than $1 / 4(27 \%)$ said that "Yes" if the Russian language 
training will be paid by migrants themselves. Only $5 \%$ of respondents are against teaching Russian to migrants, and $2 \%$ of them found it difficult to answer.

The vast majority of respondents positively assessed the interethnic climate in the region. So, to the question "over the past year, have you ever experienced a negative attitude towards yourself because of the language you speak, your nationality, religion?". $85 \%$ responded that there was no negative attitude, $3 \%$ - because of nationality, $3 \%$ because of language, $5 \%$ - found it difficult to answer.

The absolute majority of labor migrants coming to Bashkiria are from Central Asian countries, and small fraction of them are from two republics - Uzbekistan and Tajikistan, less from Kyrgyzstan. There is also a significant flow of labor migrants from the Transcaucasian countries - Armenia and Azerbaijan, although they are inferior in volume to Uzbekistan and Tajikistan. All these countries are attractive for Russian citizens in terms of tourism (historical, ethnographic, and geographical), its affordability, and the almost absence of a language barrier and cultural proximity. Apparently, based on this, about half of the respondents ( $44 \%$ each) have a positive attitude to the development of tourism in those countries from which labor migrants come to the region. Almost the same number of respondents are neutral $(47 \%$ and $45 \%)$ and a very small percentage of respondents $(4 \%$ and $7 \%$ ) are negative or have difficulty answering (5\% and $3.5 \%$ ).

During the second stage of the study, the opinion of experts was also studied. Based on the survey sample, 30 people were interviewed, including 5 people (17\%) managers, 15 people $(50 \%)$ social workers and 10 people $(33 \%)$ researchers and teachers. Of all the respondents, $7 \%$ are directly involved in solving practical issues related to migrants and migration, $30 \%$ consult on these issues, or are engaged in analytical activities, $63 \%$ of respondents had to deal with this topic, but their main activity is different.

When asked what countries in foreign Europe face migration problems and what similar risks exist in Russia, the respondents ' responses were distributed approximately equally. According to about $1 / 3$ of respondents, the risks lie in manipulating the migration topic for political purposes, $25 \%$ said that the risk lies in the inconsistent migration policy of neighboring States with open mutual borders and mutual economic obligations, $20 \%$ of respondents noted the answer "uncontrolled migration influx from other regions of the world" and "mixing the flow of economic migration and refugees", $4 \%$ found it difficult to answer.

Russia, including Bashkiria, has been facing the problem of population decline in recent years due to a drop in the birth rate and a noticeable outflow of population. The next question is aimed at identifying experts ' opinions on how to solve the problem of demographic decline in the Russian population. The largest number of responses experts noted that it is necessary to develop internal sources, i.e. to stimulate the demographic development of the country $-50 \%$. At the same time, none of the experts mentioned the answer "attract migrants from other countries", but about half (47\%) of the experts said that it is necessary to combine both of these approaches, and only $3 \%$ gave a different answer.

When asked whether foreign labor migration should be encouraged for the Russian economy, only $17 \%$ of respondents believe that it should be encouraged, while $13 \%$ do not believe that it is more important to increase labor productivity in Russia and use their labor resources. The absolute majority of respondents (67\%) believe that for the development of the Russian economy, it is necessary to combine both of these options.

According to $56 \%$ of experts, the migration situation in the region is calm and does not cause problems, but $21 \%$ said that there is a large outflow of the local population to other regions or states. The rest of the answers are less significant for experts $-12 \%$ of them said that Bashkiria is characterized by an active influx of residents from other regions of Russia that differ sharply in language and culture, as well as an active influx of foreign migrants. 
$63 \%$ of experts believe that a positive or neutral attitude towards migrants prevails in the region. At the same time, $27 \%$ of respondents believe that negative attitudes prevail in the Republic, $31 \%$ of them believe that migrants do not know the Russian language and local norms of behavior, $19 \%$ - migrants work illegally, $12 \%$ - worsen the criminal situation, and the same number believe that they increase the risk of terrorism. Other suggested answers for experts were not so significant - 7\% gave a different answer, 3\% found it difficult to answer.

$50 \%$ of experts believe that the region needs measures to adapt and integrate migrants, while $37 \%$ of respondents believe that such measures are necessary, but only for individual migrants, many can adapt themselves. $13 \%$ have a negative attitude to the migrants themselves, in their opinion, such events are only necessary for individual migrants, and many need to be returned to their homeland.

As for the question about public risks for the region, namely the risks of unemployment associated with foreign labor migration from specific states, the answers are approximately the same. Here, experts have no special preferences or biased/negative attitude towards any country, including Central Asian and Transcaucasian countries, where the main flow of labor migrants comes from.

When asked about the participation of public structures in public councils on migration issues under the authorities, $43 \%$ of experts said that their participation is extremely rare, $10 \%$ said that there is no participation at all, $7 \%$ - occasional participation, $17 \%$ - found it difficult to answer. Only $17 \%$ of experts answered about the permanent participation of public structures in public councils on migration issues under the authorities.

Analysis of law enforcement practices in the field of migration, suggestions for adjustments: extremely rare participation $-30 \%$ of experts, no participation $-23 \%$ and difficult to answer - $27 \%$. Only $10 \%$ of the experts said that they are constantly participating. Evaluation of the effectiveness of state programs that affect migration issues: extremely rare participation $-40 \%$, no participation $-13 \%$, occasional participation $-7 \%$, difficult to answer $-33 \%$. Only $7 \%$ of experts participate regularly.

$37 \%$ of experts rarely participate in conferences and roundtables on migration issues, $10 \%$ do not participate at all, $13 \%$ are undecided, and only $30 \%$ constantly participate in such events.

Speaking in the media and on the Internet about the culture of relations between migrants and the local population: extremely rare participation $-43 \%$, no participation $20 \%$, difficult to answer $-13 \%$. Permanent participation $-13 \%$, then rarely, then often $7 \%$, no reason (no such thing) $-0 \%$.

Promotion of interethnic and interreligious relations: extremely rare participation $23 \%$, no participation $-17 \%$, difficult to answer $-17 \%$. Permanent participation $-30 \%$, then rarely, then often $-7 \%$.

Promoting the study of languages and cultures of the peoples of Russia and neighboring countries in General education schools: extremely weak effect $-27 \%$, some effect $-10 \%$, no effect $-0 \%$, difficult to answer $-3 \%$, noticeable effect $-0 \%$. High efficiency $-10 \%$, no reason $-50 \%$.

Thus, the survey data showed that the local population has a favorable attitude towards labor migrants, and migrant-phobic attitudes are weak. More than half of the respondents have a positive attitude to the integration of migrants. At the same time, 1/3 of respondents hold a neutral position (not against, but not for), and only $6 \%$ said that they have a negative attitude to the integration of migrants into the local environment.

According to experts, it is not necessary to "attract migrants from other countries" to solve demographic problems. The majority of experts $(56 \%)$ believe that the migration situation in the region is calm and does not cause problems. Experts also noted (63\%) a positive or neutral attitude towards migrants. With regard to unemployment related to 
foreign labor migration, experts have no special preferences or biased/negative attitude towards any country, including Central Asian and Transcaucasian countries, where the main flow of labor migrants comes from.

\section{Conclusions and recommendations}

Negative processes in the demographic development of the Republic indicate crisis phenomena. In recent years, there has been a negative increase in the population due to migration outflow. The largest share of those leaving the Republic is young people (school leavers) who leave the Republic to enter higher education institutions in larger cities. Most of them do not return home after graduation. Also, a significant part of people of active working age due to difficult employment problems are forced to go to work in other regions, especially in the Tyumen region, KHMAO and YANAO, Moscow and the Moscow region [8].

According to the results of the survey, it can be concluded that a fairly significant proportion of the population is determined to leave the Republic for another region or even another country. The main motive for wanting to leave the region is the unfavorable situation on the local labor market. At the same time, the vast majority of respondents positively assess interethnic relations in the region. These data once again show that the Republican authorities need targeted measures of socio-economic orientation to change the migration situation in the region.

The survey data show that all population groups have a tolerant attitude towards migrants. According to $2 / 3$ of experts in the region, a positive or neutral attitude towards migrants prevails. At the same time, according to half of the experts in the region, targeted measures are needed to adapt and integrate migrants. The absolute majority of respondents unanimously believe that migrant labor is needed, especially in those areas where the local population is reluctant to go.

The study showed that migrant-phobic attitudes are quite weak in the Republic. Few of the respondents would support anti-migrant actions in the form of pickets and other public speeches. There is also a positive attitude to the development of tourism with the countries where migrants come from, and the study of the Russian language.

The results of the survey showed a weak involvement of public organizations in the process of migration relations and state migration policy. The answers to the questions that identify respondents ' opinions on various aspects of migration and migration policy indicate that public organizations have little or no involvement in the process of interaction between migrants and the local population, their adaptation and integration.

\section{References}

1. L. Khusnutdinova, K. Vildanov, L. Andreeva, R. Ilyasova, I. Gabdrafikov, Mediterranean Journal of Social Science, 6(3), 223 (2015)

2. I. Karabulatova, B. Akhmetova, H. Shagbanova, E. Loskutova, F. Sayfulina, L. Zamalieva, I. Dyukov, M. Vykhrystyuk, Central Asia and the Caucasus, 19(1), 95 (2016)

3. J. Lee, N. Rutina, Naturalizations in the United States: 2008 (2009), http://www.dhs. gov/

4. S.V. Ryazantsev, I.S. Karabulatova, R.V. Mashin, E.E. Pismennaya, S.Yu. Sivoplyasova, Mediterranean Journal of Social Science, 6(3S1), 621 (2015)

5. Employment Agency for immigrants, http://www.an-tat.ru/ 
6. N. I. Omorova, Ethnic identity of Central Asian diasporas in the ethno-political space of the Republic of Tatarstan, Auth-t Diss, For the degree of Cand. polit. sciences'. Saratov, (2015)

7. E. Nekrasova, Who benefits tomasovska Kondopoga in Bashkiria?, https://regnum.ru/

8. I. M. Gabdrafikov, Interethnic relations and religious situation in the Volga Federal district. Expert report for the year 2018, Izhevsk: LLC IPK "University", 13 (2018) 